\title{
Aristotle's Exclusion of Anger From the Experience of Tragedy
}

\section{Aristotle's Exclusion of Anger From the Experience of Tragedy*}

Stephen Leighton

Queen's University

By Aristotle's reckoning an appropriate emotional response to tragedy is centered on feelings of fear and pity. Even so, other emotions are relevant to tragedy, including love, hate, anger, wonder, surprise, and compassion. ${ }^{1} \quad$ That fear and pity should prove central is not surprising: both emotions appear frequently in Greek tragedy, and came to be associated with the understanding of poetry. ${ }^{2}$ What is surprising is the apparent exclusion of other emotions from a prominence like that of fear and pity.

This exclusion could have a variety of explanations. It could be apparent only, reflecting examples that Aristotle happens to feature. It could signify Aristotle's deference to traditional ways of seeing the matter. But while these and related explanations may be relevant, a deeper explanation also seems relevant, one having to do with the emotions themselves in the context of spectators viewing a tragedy - or so I shall argue regarding fear, pity, and anger. To prove this, I look at Aristotle's understanding of anger, contrasting and comparing it with his understanding of fear and pity. My aim is to show that and why anger is unsuited to a prominent role in the experience of tragedy, especially given the place of fear and pity. So doing will also reveal some of the roles that fear and pity can take in a spectator's response to tragedy. The argument, then, involves a study of the logic of three emotions, their natures, and their possible roles in tragedy, seen from the vantage of the emotions spectators might feel upon viewing a tragedy. If successful, it will be a key step towards understanding why other passions do not have the prominence that fear and pity do in Aristotle's understanding of tragedy.

I

Anger is chosen to test matters because it has particular promise to be construed as an emotion central to tragedy. Aristotle gives anger a role in the Poetics, and on occasion associates it with fear and pity (Poet. 1456b1). Like fear and pity, Aristotle seems to allow that there can be a catharsis of it. ${ }^{3}$ Further, Aristotle would appreciate that just as fear and pity propel much in

\footnotetext{
* This paper is held in copyright by the author and publisher. I am grateful to Ancient Philosophy for the opportunity to reprint the paper here.
} 


\section{Aristotle's Exclusion of Anger From the Experience of Tragedy}

Greek literature and tragedy, so too does anger - the anger of Oedipus, Creon, Clytemnestra, Aegisthus, the Furies, the wrath of Achilles, and so on. Moreover, as with fear and pity, Aristotle elsewhere provides a sophisticated understanding of the emotion, thereby leaving him well positioned to see and to suggest connections between anger and tragedy. ${ }^{4}$ For a variety of reasons, then, anger seems well suited to a central role in tragedy and what makes something a tragedy. Aristotle's failure to give it the prominence he gives to fear and pity is intriguing.

The roles the Poetics gives to anger include the suggestion that a poet needs to know how to portray those quick or slow to anger, while still showing them to be good (Poet. 1454b11-13). As well, Aristotle suggests that the portrayal of anger (and other passions) is more truthful and convincing when portrayed by one feeling it (1455a29-33). ${ }^{5}$ Finally, he takes the reasoning of characters to be revealed in all uses of language, including the rousing of passions, 'pity, fear, anger, etc.' (1456b1). ${ }^{6}$ Anger, then, is to be portrayed by characters, felt by actors, and expressed in the language of characters. Still, there is no clear indication that anger is to be felt by spectators of a tragedy, much less that it has the status in tragedy that fear and pity have.

It is different with fear and pity. For while fear and pity play a variety of roles in Aristotle's reflections on tragedy (including their presence in the texts of tragedies, their display on stage, and their role in shaping the action of tragedies), the experience of them in spectators in response to tragedy is noted and seems important to a play's being a tragedy. For example, in his definition of tragedy, Aristotle's speaks of fear, pity and catharsis, and is usually taken to be speaking to the reactions of spectators. Aristotle writes:

Tragedy is a representation of a serious, complete action which has magnitude, in embellished speech, with each of its elements [used] separately in the [various] parts [of the play]; [represented] by people acting and not by narration; accomplishing by means of pity and fear the catharsis of such passions (Poetics 1449b25-28). ${ }^{7}$

Later, when speaking of the construction of plots, Aristotle indicates that fear and pity are to be felt by spectators.

That which is terrifying and pitiable can arise from spectacle, but it can also arise from the structure of the incidents itself; this is superior and belongs to a better poet. For the plot should be constructed in such a way that, even without seeing it, someone who hears about the incidents will shudder [with fear] and feel pity at the outcome... Those [poets] who use spectacle to produce what is only monstrous and not terrifying have nothing in common with tragedy. For one should not seek every [kind of] pleasure from tragedy, 


\section{Aristotle's Exclusion of Anger From the Experience of Tragedy}

but [only] the sort which is particular to it. Since the poet should use representation to produce the pleasure [arising] from pity and fear, it is obvious that this must be put into the incidents (emphasis added 1453b1-14).

Both passages make being moved to fear and pity significant. ${ }^{8}$

If we can explain the apparent exclusion of anger - both why anger is not to be felt in response to tragedy, and why it does not and cannot have a prominence like that of fear and pity - it will not follow thereby that spectators of tragedy feel or should feel fear and pity, but no other passions. For all the passions that Aristotle takes to be relevant to tragedy need to be considered as passions to be felt by spectators in response to tragedy. The present consideration of anger, fear, and pity, then, is but one step forward, albeit a particularly significant one. As earlier remarks show, anger has promise as a passion spectators feel. Moreover, it has particular promise to be a passion integral to tragedy in the sense that, like fear and pity, its presence on stage and in spectators holds promise as something distinctive of tragedy and determinative of a play as a tragedy. By contrast, the other passions that Aristotle identifies, e.g. wonder, surprise love, hate or compassion, do not - even if they are on stage and are to be felt by spectators in response to tragedy. For their presence on stage and in an audience seems as plausible in comedy or any other form that might evolve, and does not seem to signal tragedy.

\section{II}

We need some understanding of the passions in question. Since the Poetics tends to deploy rather than explain the passions, consider the accounts Aristotle offers in his Rhetoric.

Fear may be defined as a sort of pain or disturbance due to imagining some destructive or painful evil in the future (Rhet. 1382a22-23).

Pity may be defined as a sort of pain at an apparent evil, destructive or painful, which befalls one who does not deserve it, and which a person might expect to befall himself or one of his own - and this when it seems close at hand (Rhet. 1385b13-15).

Anger may be defined as a desire accompanied by distress for an evident retaliation because of an evident belittlement that was directed, without justification, against oneself or those near one (Rhet. 1378a31-33).

Aristotle's depiction of the logical-causal structure of fear and pity renders them largely complementary. Both concern destructive or painful evils. In fear that concern is for great pain and the power to destroy us, for example injustice, outraged virtue, enmity, and anger when these 


\section{Aristotle's Exclusion of Anger From the Experience of Tragedy}

are present in those with the power to harm (Rhet.1382a24-b4). Pity also concerns destructive matters, for example various sorts of death, personal ill treatment, old age, disease, lack of friends, and so on (1386a5-12). In both fear and pity the pain felt regarding these destructive evils reveals a vulnerability to and concern for (rather than an indifference to or contempt of) said evils. But whereas fear's concern for destructive or painful evils is unqualified, pity addresses cases where the destructive evil is undeserved. Furthermore, pity presupposes that the person(s) one pities is 'among the good people of the world' (1385b34). Pity, then, involves an ethical concern for goodness that fear does not. Even so, both express vulnerability to evils that bring disaster: fear concerns impending disaster; pity concerns undeserved disaster.

The destructive evils that fear attends to are in the near future, not far off. Aristotle illustrates this point by observing that we all know that we shall die, but without death being at hand we take no notice and feel no fear regarding it (Rhet 1382a25-6). Fear, it seems, forewarns us of potentially destructive and painful evils that we take to be pressing. Even the signs of such matters arouse fear (1382a30-32). Presumed invulnerability or cold indifference to these matters checks fear. The case of cold indifference is interesting: Aristotle uses it to indicate that fear presupposes hope in the face of the destructive misfortune. ${ }^{9}$ Further, one sign of this hope is that fear inclines one to deliberate (1382b33-1383a8). Fear, then, not only forewarns of destructive misfortune but also helps enable one to deal with it.

The undeserved destructive or painful evil that pity concerns seems already realized. Characteristically the passion has a future orientation. To pity one must expect that one or one's own is similarly vulnerable to the evil, and soon. That is, while pity concerns the plight of another, it does so on the thought that this may soon be ours. But Aristotle also allows that pity for another can be roused by remembering 'things like this [present misfortune] happening to himself or his own' (Rhet. 1386a1-3, cf. 1385b16-18). That is, characteristically we pity another's undeserved misfortune, doing so on the basis of what seems immanent in our lives, but sometimes we do so on the remembrance of what has occurred in our lives.

Aristotle's requirement that one see a similar disaster (past or forthcoming) in one's own life or the life of one close does not render the account essentially self-directed, egotistic or egoistic. Pity's concern remains for the evils that befall another. Rather, the requirement speaks to limitations on those capable of pity, i.e. ones who anticipate or recollect the same or a similar destructive evil in their own life or ones close. Our (limited) ability to recall and anticipate restricts pity in other ways: on Aristotle's reckoning we do not pity, or not to pity in the same 


\section{Aristotle's Exclusion of Anger From the Experience of Tragedy}

way, things concerning the lives of those ten thousand years in the past or future (Rhet. 1386a2731). These are beyond our ken of anticipation or recollection. At the same time, similarities in age, character, habits, and so on better enables pity - just because it appears more likely that the same misfortune will befall us (1386a25-7). And, as with fear, presumed invulnerability to such misfortune checks the emotion, as will thoughts that one has nothing else left to suffer (1385b1924).

Pity and fear are felt on behalf of someone. In the case of fear it is on our own behalf or those close. In the case of pity it is on behalf of persons who have suffered undeserved painful or destructive evils - where we anticipate (or recollect) a similar disaster. Pity, then, is roused when others (if they are not too closely related) are under threat; fear is roused when the threat is to oneself or one's own (Rhet. 1386a16-28). Accordingly, we feel fear rather than pity where something threatens someone very close, as happened to Asmis when his son was led off to death (1386a18-22). Aristotle may oversimplify a little when he writes: 'In a word, things are fearful that are pitiable when they happen or are going to happen to others' (1382b26-27). Still, what he can claim is that the two emotions are largely complementary reactions over a continuum. Fear and pity will shade into each other as the danger shifts from the self and those close to more distant others - if the danger is undeserved, and if one can relate to a similar matter either by recollection or anticipation. So seen, the two passions can be co-present: the pity we feel for a neighbor might be the source of fear for oneself and family. At the same time, Aristotle also allows that persons so fearful as to be 'scared out of their wits' have no room for pity because they are 'so taken up with their own suffering' (1385b31-5). Presumably, this was Asmis' fate.

Before proceeding to anger, I should note how certain claims made in Poetics serve to qualify what we have just seen. Most notable is the Poetics' claim that disaster befalling decent people is shocking, not fearful or pitiable (Poet. 1452b34-36). This is unanticipated by and unexpected in the accounts of fear and pity in the Rhetoric and elsewhere: one would have supposed that such disaster could be feared or pitied. By separating the shocking from the pitiable and fearful, Aristotle seems to be restricting fear and pity to the characters that he takes tragedy to concern, i.e. those who are neither superior in virtue nor who undergo misfortune because of vice and wickedness (1453a7-10). Again, whereas the Rhetoric takes fear to be felt on behalf of oneself and those close, the Poetics speaks of it being felt on behalf of those like [ourselves] (1453a5). This is an obscure remark but one that seems to emphasize a similarity 


\section{Aristotle's Exclusion of Anger From the Experience of Tragedy}

between the person feeling fear and the person on whose behalf one feels the fear. If so, this too serves to restrict our fear to the sorts of characters that Aristotle takes tragedy to deal with.

Anger shares features in common with fear and pity. Like fear, anger displays concern for oneself and those close, rather than more distant others. Like fear and pity, the pain of the emotion reveals a concern for (not an indifference to or contempt of) the matter that gives rise to the emotion. But whereas fear and pity express concern for our vulnerability to painful or destructive evils, anger's pain does not express vulnerability, but affront, affront at an evident belittlement.

Belittlement is a form of voluntary and unprovoked unjust treatment by others, one which dishonors the belittled (Rhet. 1378b10-11, b22-5, 1379a31-33, 1380a14-17). It involves the failure to take another seriously, instead treating her or him as having no worth, for good or evil (1378b10-13, b29-31). It has three major forms: spite, insult and insolence; and its manifestations can range from the forgetting of names to rejoicing in another's misfortune (1378b13-14, 1379a28-b29, b17-36). Anger, then, takes affront at a highly specific mistreatment, an unprovoked, unjustified dishonoring. Anger's concerns, then, are quite distant from fear and pity's concerns for pain and destruction.

And whereas fear forewarns of specific misfortunes and helps enable us to respond, anger's affront at belittlement is strikingly reactive. Aristotle makes it clear that angry persons aim to retaliate, and retaliate against the person(s) who belittles them (Rhet. 1378a34-5). Of course, anger and revenge are not necessitated where there is belittlement. It can be calmed by the person who insults admitting and repenting their slight, humbling themselves, fear of or pity for the person belittling, and so on (Rhet 1380a9-1380b1). But where it is not offset, anger's retaliation is highly personal: not only is the retaliation directed toward the person(s) who belittled, but also angry persons are not satisfied in taking revenge unless their belittlers know that it is retaliation they now suffer (1380b20-27). It is, in its way, a comparatively optimistic reaction in the sense that it presumes its revenge and a kind of redressing can be achieved.

The role for retaliation makes anger's affective nature complex in ways not seen in fear and pity. Like fear and pity, anger is a painful reaction. But anger's retaliation and even the anticipation of retaliation bring pleasure to the angry person (1378b2-9). The failure to achieve revenge, when not offset by other considerations, is frustrating and proves particularly painful to the angered person (EN 1126a19-25). So seen both anger's nature and its sentience are 


\section{Aristotle's Exclusion of Anger From the Experience of Tragedy}

considerably different from fear and pity. Further, in ways we shall need to explore, anger proves to be an emotion opposite to fear and pity. ${ }^{10}$

III

Consider the prospects for tragedy provoking the emotions of spectators. Given Aristotle's understanding of fear and pity, and the situations depicted in tragedy, one can suppose that the plots might well beget fear and pity in an audience. Taking the characters on stage to be like us, we might feel fear on behalf of Oedipus because of the danger he is in. So too, we might pity Jocastra or her children for the undeserved disaster suffered.

To be sure, there can be problems in just how to understand this. Barnes 1995, ch. 9 esp. 277-278 raises a number of concerns. For example, if pity requires an expectation of the disaster soon befalling oneself or one's own (as its definition indicates), then it seems that pity for Oedipus' children requires that spectators suspect that their own fathers will soon bring disaster to the family through having killed their fathers and slept with their mothers. So understood, not only is Aristotle's analysis of pity overly restrictive concerning cases that normally would be characterized in terms of pity, but also its application in the theatre means that very few can pity Oedipus' children.

Various solutions might be proposed. For example, it is often supposed that poetic appreciation involves some kind of identification with a character, her or his situation and concerns. ${ }^{11}$ If so, then pity becomes possible through and to the extent of identification with certain characters - even though one does not thereby personally suspect such disaster will haunt one's own life. ${ }^{12}$ This role for identification, however, seems an interpolation rather than interpretation of the Poetics.

A solution that keys on Aristotle's account of the emotions could emphasize his observation that fear and pity can be felt where the disaster concerns those close to one or others whose disaster can befall somebody close to one. For if spectators can take those on stage to be close (or like) rather than simply distant strangers, then a spectator's fear or pity need not require the expectation that the disasters on stage threaten them personally. ${ }^{13}$ If so, we can pity Oedipus' children because we can take them to be sufficiently close to us. Furthermore, we should recall that while Aristotle's definition of pity speaks of anticipating the disaster befalling oneself or one close, he goes on to suggest that pity does not require that one imagine the same evil pressing, just 'of the sort mentioned in the definition or like it or about equal to it' 


\section{Aristotle's Exclusion of Anger From the Experience of Tragedy}

(Rhet.1385b18-19). That is, pity for Oedipus's children does not require that one consider that the same undeserved disaster threatens one. Pity can be had if one has experience of undeserved disaster like or about equal to that of the stage character. Moreover, it should be noted that the plausibility of the objection depends on presuming that what is pitied is specified in a very detailed way, i.e. the disaster that befell Oedipus's children specified in its fullness. But were one to allow that emotions can operate with more general descriptions than, say, the particularities of incest, then the objection loses much of its power. For it seems easy to grant that spectators might pity Oedipus' children for their undeserved plight if one does not require that pity therein expresses a concern for all the particularities of said plight befalling oneself even if it is caused by said particularities. The previous point that one imagines an evil 'like it or about equal to it' is some support for suggesting that this is how Aristotle sees matters. Further evidence that this is how Aristotle understands the matter (at least in the context of poetry) is to be found in his thought that poetry's concerns are for something more universal than are history's (cf. Poet 1451b1-11). That is, the level of description at which poetry operates is more abstract than that of history. In this way, the particularities of incest are not needed in the specification of the object of pity. ${ }^{14}$

Thus there seem to be several ways in which we can understand how Aristotle might have supposed that an audience's response to tragedy would involve being moved to fear and pity. If so, we can make sense of the audience feeling fear or pity via the presence on stage of the fearful and pitiable. Can we not say something similar about anger and the belittling? Tiresias is treated abominably by Oedipus; Antigone, by Creon. Surely, there is belittlement in this; surely, Tiresias and Antigone have cause to be angry over their treatment. Since Aristotle allows that anger can be roused at the belittling of those who are close, can not spectators be roused to anger through such belittlement?

The answer, I suggest, is more problematic than might be presumed.

IV

The problems that I shall bring forward do not revolve on doubts that certain characters genuinely belittle others, or that spectators recognize this, or that spectators can consider belittled characters to be sufficiently and appropriately close to be angered on their behalf. For on all these matters the rousing of anger seems as plausible as is the rousing of fear or pity. ${ }^{15}$ Even so, I suggest that there are structural features of anger that render it an unsuitable or impossible 


\section{Aristotle's Exclusion of Anger From the Experience of Tragedy}

response in the context of tragedy, especially given the place of fear and pity. Three related concerns are important: anger's opposition to fear and pity, anger's teleology, and anger's lack of clarity.

Consider first anger's opposition to fear and pity. Earlier I suggested that anger is opposite to fear and pity in various ways. The oppositions bear on matters here, providing reason not to include anger as an emotion appropriate to tragedy. The problems include the possibility and suitability of reacting with anger and also fear or pity.

One manifestation of the opposition is to be found in the physiology of the emotions. While the definitions offered earlier do not speak to their physiology, Aristotle takes their material cause to involve particular physiological configurations ( $D e$ An. 403a26-b19.). The material nature of both anger and fear is centered in the heart (cf. 408b7-11). But whereas fear involves cooling and chilling, anger involves heat and boiling (cf. PA 650b27-651a3, Prob. 898a4-7). Accordingly, if a person is to be moved to anger and fear, the same area of the body must be heating and cooling. Since this is not feasible, and since the point is appreciated in works by Aristotle and from his school (Iuv. 479b19-25, Prob. 947b23-948a12), and since fear's role in tragedy is assured, the physiology of these emotions leaves Aristotle no room to contemplate or recommend anger in response to tragedy.

Fear's opposition to anger is not only based on the physiology of these emotions, i.e., their material nature, but also on formal features of their structure. Aristotle observes that in the grips of fear we do not feel anger, and when angry we do not feel fear. Aristotle associates anger with good hopes, which, in turn, make one lack fear. Anger seems to embody an outgoing, aggressive boldness that conflicts with the concern for danger expressed in fear. Fear, in turn, excludes anger. This would seem to be explained by the fact that being pressed by imminent danger as one is in fear, leaves little room to be concerned with anger's belittlement, and vice versa (cf. Rhet. 1380a32-3, 1389a26-28).

Pity too is opposed to anger - as can be seen in its calming of anger (Rhet. 1380b13-16). Anger's opposition to and exclusion of pity also can be seen in the fact that courageous emotions (including anger and confidence) make persons incapable of pity (1385b29-34). Part of the explanation of the opposition and exclusion is that emotions like anger and confidence do not take account of the future, whereas pity does. ${ }^{16}$ For one who pities sees a pitied person's trauma as one 'which a person might expect himself or one of his own to suffer' (1385b14). ${ }^{17}$ Another part of the explanation would seem to have to do with the concerns of each. Those who pity see 


\section{Aristotle's Exclusion of Anger From the Experience of Tragedy}

the pitied in terms of undeserved misfortune. To see another in these terms is not to see them as an agent who belittles and acts unjustly (i.e., as an agent who elicits our anger). Aristotle's understanding of the ultimate concerns of the two emotions renders them strikingly dissimilar: suffering undeserved misfortune versus belittlement. In consequence, anger focuses one's attention in a quite different way than were one to pity, leaving no room for pity (and vice versa).

These observations reveal certain ways in which anger is incompatible with fear and pity. In consequence audiences can not be moved to fear and/or pity and also to anger, and vice versa. If so, the building of the emotions of tragedy through the tale is frustrated if the tale also engenders anger. Fear and pity undercut anger; anger undercuts fear and pity. Thus the prominence of fear and pity in tragedy leaves no room to include anger as an emotion of tragedy. ${ }^{18}$

\section{V}

Arguably, there are ways around these problems. Problems of compatibility, and the imputed difficulties this creates for spectators on viewing tragedy, might be surmounted if the emotions integral to tragedy are to be felt in a quite piecemeal way (rather than as a generalized and sustained emotional response). Perhaps this makes room for anger as well as fear and pity whatever the incompatibilities amongst these emotions.

This response suits Aristotle's understanding of the emotions in the sense that emotions are quite specifically directed: anger is directed to the person belittling; fear, to the danger present; pity, to the undeserved disaster, and so on. Aristotle views the emotions as highly structured responses, not undirected or amorphous feelings. Accordingly, one might suggest that rather than reacting with fear and pity generally to the play, fear is to be directed towards Oedipus regarding what will unfold, pity to his children for their undeserved disaster, anger to Oedipus for his treatment of Tiresias, and so on. If so, then so long as the emotions are appropriately directed, the alleged problem of incompatibility seems to be avoided.

I suggest, however, that a piecemeal approach to the emotions of tragedy is not satisfactory. At a physiological level the presence of fear still undercuts anger, and vice versa. This difficulty of experiencing fear (or pity) and anger remains, howsoever these emotions are directed. Moreover, the piecemeal proposal requires that spectators keep their emotions and the concerns involved quite straight and separated from each other - if spectators are to react 


\section{Aristotle's Exclusion of Anger From the Experience of Tragedy}

appropriately and get the appropriate pleasure. Otherwise, the physiological and logical opposition between anger and fear and pity, and vice versa, emerges once more.

Aristotle's understanding of the emotions, however, does not support such stringent requirements. Although emotions are highly structured and directed responses, Aristotle does not think that they are fully bounded by judgment. As features of the non-rational soul, emotions share in reason in a way, both listening to and obeying reason, but doing so akin to a child's reaction to a father's advice (EN 1102b13-3a4). As Aristotle understands this, there is some tendency for emotions to follow reason, but they remain unruly and disobedient. Consider, for example, that they tend to spread beyond their original focus. Aristotle's recounting of the story of Ergophilos, who did not receive the consequences of the Athenians' anger with him because it had already been spent on another, is but one example (Rhet. 1380b7-13). As well, consider that emotions roused persist in the sense that they are self-sustaining and not readily overturned by efforts to the contrary:

For a similar reason bursts of anger or fits of terror, when once they have excited such motions, are not at once allayed, even though the angry or terrified persons set up counter motions, but the passions continue to move them on, in the same direction as at first (Mem. 453a26-29).

In view of such thoughts on how the emotions work, the idea of simply moving between emotional responses, anger towards this, fear regarding that, pity for that, back to anger, etc., where the reactions are to be kept clearly distinguished and separated from one another - lest their logical and physiological oppositions emerge once more- is unpromising. Aristotle's understanding of the psychology of the emotions does not find feasible what the piecemeal proposal requires, but instead suggests an unfolding and self-sustaining reaction. If so, then at a psychological level the emotions will not be kept separate, and the conflicts anger has with fear and pity will re-emerge. Once more, Aristotle has good reason to exclude anger from the experience of tragedy.

At a more poetical level there are profound difficulties as well. For even if the problems created in trying to keep all of one's reactions straight did not press, Aristotle has good reason not to think of the emotions of tragedy in the way the piecemeal proposal implies. For Aristotle's depiction of tragedy is not, as the proposal implies, an emotional roller coaster, being wrenched now this way, now that. Unlike epic, in which many tales are possible, tragedy is to be the unfolding of one tale (Poet. 1451a18-19, 25-35). That unfolding has a place for discovery, 


\section{Aristotle's Exclusion of Anger From the Experience of Tragedy}

and reversal, but throughout has a unity to it, centered on the hamartia of a character (cf. 1453a10-16, 1454b35, 1459a17-25). Spectators' emotional responses are best when they are in response to the unfolding of these incidents (1453b1-4). Throughout, fear or pity mount, centered on a character missing the mark, rather than spectators shuffling from emotion to emotion to emotion. In this way we can understand how Aristotle might anticipate a catharsis of the emotions through the events of the play, and the peculiar pleasure of tragedy. To imagine instead numerous emotional reactions, including anger, will create an emotional cacophony in the spectator that risks the catharsis and the pleasure of tragedy. But with anger and its opposition to fear and pity out of the picture, with fear and pity centered in the way suggested, the problem created for unity in reaction is removed. ${ }^{19}$

Before moving to other considerations, I should observe that the foregoing considerations do not deny that fear and pity can and do come into tension with each other. We noted earlier that extremes of fear drive out pity (cf. Rhet. 1385b32-35). As well, the story of Asmis indicated how fear for someone can usurp pity for them; the dreadful can drive out the pitiable, doing so when the dreadful is very near (1386a19-25). Thus it would seem that in tragedy the playwright must balance the emotions of tragedy. ${ }^{20}$ But whereas fear and pity must be balanced in tragedy and in the reactions of spectators, anger is incompatible with fear and pity, and unsuited to them.

\section{VI}

Oppositions amongst emotions are not the only matters that reveal anger as an impossible or unsuitable response to tragedy. So too does anger's teleology. As depicted by Aristotle, anger is strikingly reactive: the definition speaks of a desire to retaliate against one's belittlers. Moreover, the persons suffering retaliation are to know that their pain is a matter of anger's vengeance (1380b20-26). In light of this, a spectator's anger with Oedipus or Creon risks transforming her or him into a participant or one who interrupts the drama. While a contemporary sensibility might find these intriguing and even welcome prospects, it is hard to see these as apt reactions to Greek tragedy: they undercut the very role of spectator, not to mention the completion of the play itself. ${ }^{21}$ Once more, including anger as an emotion that spectators are to feel proves unsuitable.

The point of this objection is not to deny that audiences can and have responded with anger to what is on stage, but to say that where so it is not a valuable response in the context of tragedy. The appreciation of the play is lost or seriously impaired: the role of spectator has 


\section{Aristotle's Exclusion of Anger From the Experience of Tragedy}

changed to participant or disrupter. Engagement in the particular pleasure of tragedy is forsaken for practical and here inappropriate matters.

It is significant that fear and pity do not seem beset with similar difficulties. For while final causality with the quite specific aim of retaliation is critical in Aristotle's understanding of anger, the definitions of fear and pity do not speak of a specific aim or even a general aim. We might depict fear in terms of freezing and flight, but Aristotle does not. Thus whereas Aristotle's account of anger risks moving the spectator of the play to a participant in or disrupter of it, his accounts of fear and pity do not. Indeed fear and pity are understood in ways that can foster a spectator's role. For in being moved by fear or pity a spectator's attention is drawn to the danger or undeserved misfortune of the characters. Their attention so drawn, but without specific aims or desires, spectators can better appreciate features of the tale that move them, both by virtue of their concentrated attention and its focus upon matters of disaster and undeserved disaster. This can enable a deeper appreciation, and does so without thereby begetting action or even consideration of it. If so, then Aristotle's analysis of these emotions renders anger particularly unsuitable in a spectator, whereas his analysis of fear and pity can foster a spectator's appreciation. Once more, Aristotle has good reason to exclude anger as an appropriate reaction to a tragedy, but to endorse fear and pity.

A further expression of these teleological differences is to be found in the sentient nature of these emotions. All three emotions are defined in terms of pain. But Aristotle also calls attention to pleasures inherent in anger. The revenge that anger aspires to is pleasant in its contemplation as well as its realization (Rhet. 1378b2-9). These pleasures exacerbate the problem of the appropriateness of anger. A desire for revenge (even if not acted upon) will prove diverting to one's activities as a spectator. Moreover, pleasure in anticipating revenge can only further divert a spectator's attention — as would pleasure in achieving revenge. By contrast, because fear and pity lack a similar teleological bent, Aristotle describes no pleasures inherent in them. Fear and pity, then, do not have a diverting aim or diverting pleasures of anger.

The difficulties that anger's pleasures create for Aristotle's account of tragedy are usefully seen from a different angle. When Aristotle speaks of the particular pleasure of tragedy, he makes it clear that not just any pleasure is relevant, and that only some are to be sought. The relevant pleasure is to arise through fear and pity (Poet. 1453b10-12, quoted above). Because fear and pity are not themselves pleasant, the particular pleasure of tragedy cannot be a pleasure inherent in the emotions fear and pity. However, catharsis of emotion brings pleasure. ${ }^{22}$ 


\section{Aristotle's Exclusion of Anger From the Experience of Tragedy}

Without trying to determine the matter too finely here, a reasonable understanding of Aristotle's position is that the particular pleasure of tragedy that has to do with fear and pity arises through a catharsis of these emotions (however exactly catharsis is to be understood). ${ }^{23}$

Perhaps a similar account regarding anger will be proposed. For anger seems to admit of catharsis, a matter of pleasure to the person. Arguably, then, the pleasures of anger's catharsis created upon viewing a tragedy could be included in the particular pleasure of tragedy. However, differences remain. As we have seen, anger has its own pleasures. These pleasures are not themselves the particular pleasures of tragedy (particular pleasures of tragedy, I have argued, arise through the catharsis of emotions). If so, the catharsis of anger while pleasant in itself is accompanied by other pleasures (those integral to anger). The presence of these latter pleasures will prove diverting, diluting, and clouding of the particular pleasure of tragedy created through catharsis, and therein the experience of tragedy. This is important because Aristotle tells us that tragedy is not to involve every pleasure but only the pleasure particular to it (Poet. 1453b11, cf. 1453a35-36, 1459a21, 1462b11-13). Thus even if anger's catharsis can beget a pleasure that might be particular to tragedy, anger's internal pleasures serve to divert, dilute, and cloud the emergence of the particular pleasure of tragedy. Far better, then, that the experience of tragedy be without this diluting and diverting emotion. ${ }^{24}$

\section{VII}

The arguments in the preceding section show that and how differences in teleology render anger an inappropriate reaction to tragedy, while allowing fear and pity to be appropriate reactions. Some objections to the understanding of anger and that of fear and pity can be anticipated and deserve our attention. I confine the arguments to issues of teleology rather than associated problem of sentience, since the former serves as a basis for the latter. I begin with anger.

Anger's teleological nature was seen to be disruptive of a spectator viewing a tragedy, and, perhaps, the performance of the tragedy itself. These difficulties might be deflected by taking anger not to be specifically targeted, or by breaking the link to activity through the elimination or the suppression of desire.

If anger can be experienced in ways that do not target particular persons, then a spectator roused to anger need not react against Oedipus or Creon, and the difficulties of a spectator becoming a participant or disrupter are diminished. This proposal, however, is unsuited to 


\section{Aristotle's Exclusion of Anger From the Experience of Tragedy}

Aristotle's understanding of anger. Aristotle holds that anger (unlike, say, hate) is targeted at the individual who rouses it (Rhet. 1378a32-b1, 1382a4-6). He does not allow one to retain anger yet shift the concern from the particular targeted to a more generalized target. And even were this not so, the angry spectator would still want to react, to take vengeance. It might be true that their anger would not be focused on Creon or Oedipus, but anger's desire for evident vengeance would remain. This desire might be acted upon, once more turning the spectator into a participant or disrupter of the tragedy. And even were the desire not acted upon, its presence would remain disrupting and distracting to a spectator appreciating the tale of tragedy. If so, the contrast between anger and fear and pity has not been diminished. Anger remains disruptive and distracting in ways that fear and pity are not.

A more promising suggestion is that angered spectators are to eliminate their desire for retaliation. For if so, then anger proves not interfering in the ways suggested. That anger might exist without any desire to retaliate is something we might allow for, and is something that Aristotle takes seriously (Top. 156a30-b2). Yet while Aristotle grants that retaliation may be quite mild in certain cases, he insists that the aim to retaliate and the retaliation remain. Elsewhere too Aristotle seems impressed by anger's connection to revenge. He quotes with approval Heraclitus' thought that it 'is difficult to fight against anger $(\theta v \mu \bar{\varsigma})$; for a man will buy revenge with his soul' (Pol. 1315a30-31). So too a prominent place for revenge is given in Aristotle's other characterizations of anger (cf. De An. 403a26-28 and Top. 156a32). Because the elimination of the desire for revenge from anger is not possible on Aristotle's view, the contrast between anger and fear and pity stands. Again, anger remains disruptive (and distracting) in ways that fear and pity are not.

The most promising suggestion is that angered spectators should suppress anger's desire for revenge. Aristotle's thoughts on the suppression of desire are not fully developed, but it is clear that anger's desire can be suppressed. If so, the spectator will become neither a participant in nor a disrupter of the tragedy. There remains a cost, however. The anger remains unfulfilled and painful. Those who are not able to release their anger are bitter and smolder until vengeance is taken; if it is not taken, they hold a grudge. Moreover, digesting anger takes time, and persons who do so are thought troublesome to themselves and friends (EN 1126a21-26, cf. Rhet. 1380b57). Thus while anger with its desire for revenge suppressed avoids the participant/disrupter problem, other problems remain. For the pain aroused by the suppression of desire introduces a considerable degree of conflict and continuing disturbance in a spectator. This too will divert 


\section{Aristotle's Exclusion of Anger From the Experience of Tragedy}

spectators in their roles as spectators. So while some of the difficulties have been offset, anger remains particularly unsuited to tragedy. Fear and pity do not seem beset by similar difficulties, and therein are much more suited to the aims of tragedy.

Given all this, one might hope to resolve these problems with a technical, poetical, nonteleological understanding of anger. Were such an understanding available and feasible, the problems associated with anger's teleology might be skirted. Yet Aristotle's thoughts about anger on a non-teleological rendering (in the Topics, discussed above) suggest that he at least does not think this feasible. Moreover, as far as we can tell, he did not attempt to come to a distinctive, technical specification of the emotions, one that might be appropriate to poetry. ${ }^{25}$

We should reconsider fear and pity. For if diminishing the contrast between anger and fear and pity cannot be achieved by diminishing anger's reactive nature, perhaps a reconsideration of fear and pity will show them to be more reactive than so far allowed. If so, then the problem of disruption and moving from spectator to participant is not peculiar to anger (but likewise affects being roused to fear and pity). If so, there would prove to be no special reason to exclude anger on teleological grounds, after all.

In order for this strategy to be wholly persuasive a teleology like that found in anger would need to be established for fear and pity. Since none is announced in the definitions of either emotion, nor explicitly taken up in the ensuing discussions, the position must be that a teleological structure like that of anger is implicit all the same. Support for this position can be garnered by noting that fear and pity (like anger) are pains. Since Aristotle holds that pains repel (De An. 431a8-16), some action through these emotions can be explained. Further support can be garnered by noting that on Aristotle's reckoning fear involves a hope for safety and makes people able/liable to deliberate ( $\beta$ ov $\lambda \varepsilon \cup \tau \imath \kappa o v \square s \pi 01 \varepsilon 1 \square$, Rhet. 1383a6-8). Taken together, these can explain how in the grips of fear we are warned off certain things and drawn to others. So seen, fear should be understood to have teleological implications that explain action through emotion. If so, anger is not to be sharply distinguished from fear and pity in terms of teleological structure, and is no more likely to be disruptive of tragedy.

While there is much correct in this objection, the conclusions do not follow - especially in the context of a performance on stage. It is certainly true that fear can be used in the explanation of action. ${ }^{26}$ Still, where it does elicit activity, the genesis of that activity differs considerably from anger's. More particularly, anger desires retaliation, and so of itself motivates retaliatory action. It is a quintessentially practical emotion. Fear and pity, by contrast, do not 


\section{Aristotle's Exclusion of Anger From the Experience of Tragedy}

themselves have a parallel role for desire, do not necessarily desire or beget action. And where they do lead to action, the manner is most indirect and significantly different. For example, the argument for activity via the painfulness of fear (if indeed it does require activity), does so in a wholly unspecific way, and may be satisfied by something as innocuous as flinching or averting one's eyes. Thus while fear can be connected to activity, it need not be in a way that would prove particularly disruptive of a tragedy.

The observations that fear makes persons able or liable to deliberate, and that fear has a hope for safety provide greater promise for significant activity through fear. Yet these connections to activity are through a capacity or liability to deliberate. Fear does not require deliberation. ${ }^{27}$ Moreover, even where deliberation does occur, the actual ends to which deliberation is tailored may or may not be given by fear. Presumably, in certain contexts (the battlefield, for example) a hope for safety together with an ability or liability to deliberate leads one to deliberate about one's safety and thereby to flee or to fight or to other action. Still, fear itself does not require that one deliberate, nor that one deliberate in terms of those ends. Thus it remains perfectly possible for fear's deliberative ability or liability, when actuated, to be so in terms of a variety of ends - something that stands in sharp contrast to anger's connection to revenge. Moreover, even where fear leads to deliberation and the deliberation is in terms of safety, it is (I shall suggest) unnecessary that it does so in ways that lead to activity. If so, a significant contrast between anger and fear and pity remains.

Imagining a spectator viewing a tragedy will help us to see some of the above claims. In the Antigone Creon's wild and unbridled anger towards Antigone - though it may not have moved her to fear him - certainly can be understood to move a spectator to fear on behalf of her. Arguably the simple knowledge that one is at the theatre will ensure that a spectator's ability or liability for deliberation (via their fear) is not activated here. ${ }^{28}$ Where so, fear is felt but without being causal (or tending to be causal) of a spectator's action. But even should a spectator's deliberative capacity be activated, the foregoing analysis makes clear that it need not (though can) concern the ends of safety. And even where the capacity is activated by the dangers borne of Creon's anger, and done so in terms of hopes for her safety, that concern may be expressed in terms of what Antigone might do, should do, should have done. Where so, a spectator's deliberation can contribute to her or his understanding and appreciation of the situation, but not thereby to his or her own actions or that of the characters. If so, then the context of a spectator at a tragedy taken together with the hope for safety through roused fear serve to shape the ends of 


\section{Aristotle's Exclusion of Anger From the Experience of Tragedy}

deliberation in a way that contributes to a deeper appreciation (but not therefore to action or disruption) of the play. Thus when Aristotle notes that even the indications of danger rouse fear (Rhet. 1382a30-33), we can envisage an audience grappling, considering, working out matters raised by their fear on behalf of Antigone, without that being a working out of their own actions. Spectators' appreciation of the play deepens through their fear, doing so without turning them into participants in or disrupters of the play. This is remarkably different from anger's far more direct, highly personal, connection to revenge, and letting the person upon whom it is taken know of the matter.

The point of the above vignette is not to insist that a particular deliberative path (and this only) occurs in those moved to fear upon seeing the Antigone. For if the understanding of fear here offered is correct, fear can have a number of realizations. Some of these may not involve deliberation at all; others may involve deliberation and further insight but not action; still others may be wholly practical, involving both deliberation and action on the part of one experiencing fear. What is most significant is that there are realizations of fear which do not lead to action, but to a deepening of understanding. If so, this shows how Aristotle's conception of fear can deepen one's appreciation and not be disruptive. This, in turn, emphasizes the point that any connection from fear to deliberation to action contrasts sharply with Aristotle's understanding of anger as a practical emotion connected to revenge. Fear is specified in a way that is open-ended about whether any action is to be taken, and what action (if any) is to be taken. This stands in contrast to anger's teleology: its connection to revenge is fundamental to its definition, something that is followed up in Aristotle's articulation of the emotion. If so, then when thinking of a spectator viewing a tragedy, anger continues to have the problems raised in the previous section, problems that fear and pity do not have. For while all three emotions might be roused in response to a tragedy, anger quickly moves one from spectator to participant, but fear (and pity) do not. ${ }^{29}$

The conclusions of the preceding section are reaffirmed. There are differences in the teleological structure of anger versus that of fear and pity that render the latter suited to tragedy and the former unsuited.

\section{VIII}

Finally, consider the comparative clarity of anger. The evocation of the spectators' emotions that most interests Aristotle comes in response to the incidents rather than tragedy's spectacle (Poet. 


\section{Aristotle's Exclusion of Anger From the Experience of Tragedy}

1453b1-3). We have seen that a certain sort of unity structured round the tale can help achieve this. It is reasonable to suppose that spectators can best appreciate the tale with a comparatively clear mind. We have considered that and how fear's connections to deliberation can foster a better appreciation of the tale. I suggest that anger's prospects for the same are comparatively dim, particularly when anger manifests itself as rage $(\theta v \mu \circ \varsigma)$. The point, once more, is to suggest that anger is comparatively ill suited to tragedy.

As we have seen, Aristotle does not affirm a connection between anger and deliberation parallel to that of fear. This itself is an indication that anger is less useful to a better appreciation of tragedy's tale - and thereby less amenable to insight, catharsis and the peculiar pleasure of tragedy. Various remarks Aristotle makes about anger tend to corroborate this. For example, Aristotle likens its operation $(\theta u \mu \rho \varsigma)$ to that of a hasty servant who vaguely attends, hears but does not hear the order given, misconstrues the matter, then reacts to retaliate on this basis ( $E N$ 1149a25-b1). Anger seems an emotion that can be roused quickly (cf. 1173a29-b5) and one that serves to conceal (cf. S. El. 174a16-29). As well, its pain impedes reason (Pol. 1312b30-4). Like the effect of smoke stinging our eyes, it clouds our reason $(F .660)$, and makes it depart (Rhet. ad Alex. 1429a19-21). Its effects are hard to combat (EE 1223b20-23, Pol. 1315a30-2). Moreover, that anger is associated with confidence and not taking account of the future (Rhet. 1385b29-31) can only serve to worsen matters inasmuch as one is left content with any misimpression anger brings.

So construed, anger seems a poor candidate for an emotion integral to tragedy. Its arousal seems to impede the clarity of mind needed for a better appreciation of tragedy's tale.

Arguably, some of the passages just cited speak to anger's excesses. But even if we could presume that all these passages speak to anger's excesses (which we should not), the comparative frequency with which Aristotle warns of anger's difficulties would itself make anger suspect in the present context. After all, anger's appropriateness to ethical character need not entail its appropriateness in response to tragedy.

As before, I do not wish to overstate the contrast between anger and fear and pity. Pity and anger both can serve to warp a judge's judgment (Rhet. 1354a23-5); fear and anger roused can lead to misinterpretation and deception (De An. 460b1-27). Anger can be appropriate; fear and pity can be inappropriate. One form of an inappropriate emotion would involve confusion, lack of clarity; appropriateness in emotion can beget insight. But while all three emotions can be appropriate or not, be more or less clear, fear and pity can foster insight, whereas anger in a 


\section{Aristotle's Exclusion of Anger From the Experience of Tragedy}

variety of ways tends less to clarity. If so, then anger, in addition to its problems of teleology and incompatibilities with fear and pity, is a comparatively uninsightful reaction to a tragedy. That would seem to make it an unsuitable emotion for a spectator to feel.

\section{IX}

The argument has run its course. While a variety of emotions have some role in tragedy, anger, unlike fear and pity, is not an emotion spectators should feel. We see why Aristotle does not give it the prominence he gives to fear and pity. Anger's teleology is inappropriate to the purposes of tragedy, moving one from spectator to participant. Anger is opposed in a variety of ways to pity and fear. Some of these ways make anger impossible if fear or pity is felt; others frustrate fear and pity and the proper appreciation of a tragedy. Further, anger's comparative lack of clarity impedes thought and thereby the ability to appreciate tragedy's plot. In contrast fear is more amenable to thought and thereby the ability to appreciate tragedy's plot. Thus Aristotle is best understood as limiting the emotions that an audience responds with, giving fear and pity a place that anger does not have. Of course, audiences may react differently, and poets may have sought to rouse an audience's anger, but when so the ends of tragedy are impeded.

Let me close quite speculatively. In grappling with Aristotle on fear and pity, and the prospects for anger as a proper and integral response to tragedy, in addition to trying to make best sense of the text and the overall argument, we are trying to gain some sense of what we might call Aristotle's understanding of "the tragic." Because we understand that Greek tragedies dealt with matters of disaster and undeserved disaster, we can understand why Aristotle would credit fear and pity as distinctive of tragedy. So seen, tragedy moves us by and faces us with the prospects of being crushed by disaster, and speaks to ways in which we humans come to deal with this. Matters of belittlement are considerably different from matters of deserved and undeserved disaster. However, given Greek literature and the tragedies, it is reasonable to postulate that human belittlement is also relevant to tragedy. Accordingly, the place of anger in Aristotle's Poetics, and its prospects to be included as part of Aristotle's sense of the "the tragic" is worth pondering. If the arguments offered here are correct, Aristotle has not included or allowed for anger to have a place akin that of fear and pity. Interestingly, he has not dismissed anger because its concerns are somehow outside the boundaries of what might be seen to be "tragic," but because in a variety of ways a response of anger on the part of an audience is at 


\title{
Aristotle's Exclusion of Anger From the Experience of Tragedy
}

odds with responses of fear or pity. ${ }^{30}$ Thus including anger would risk the very success of the form tragedy, structured as it is in terms of fear and pity. ${ }^{31}$

Stephen Leighton

Queen's University,

Kingston, Ontario

\begin{abstract}
${ }^{1}$ Their roles are various. Reference to fear ( $\left.f \circ b \circ j\right)$ in the Poetics is extensive, including 1449b27, 52a2, a26, b1, b32, b36, 53a1, a4-6, 53b1, b9, b12, 56b1. So too is reference to pity (el eoj ), including 1449b27, 52a3, a38, b32, b36, 53a1, a3, a5-6, 53b1, b5, b12, b17, 56b1, b3. Wonder (qa uma s t o l ) is mentioned at 1452a6, 56a20, 60a12, a17; love ( $\mathrm{il} \mathrm{i} \mathrm{b}$ ) is mentioned at 1452a31, b19, 53b31; hate (ex qr o j) is mentioned at 1452a31, 53b16-17, 55b22; surprise (ek pl h cij) is mentioned at 1454a4, 55a17, 60b25; compassion ( $\mathrm{il} \mathrm{anqr} \mathrm{w} \mathrm{p} \mathrm{i} \mathrm{a}$ ) is mentioned at 1452b38, 53a2, 56a21. Emotional repercussions that Aristotle disapproves of in the context of tragedy include what is only monstrous (t er a t w $\mathrm{dh} \mathrm{j} \mathrm{,} \mathrm{1453b9)} \mathrm{and} \mathrm{what} \mathrm{is} \mathrm{shocking} \mathrm{(mi} \mathrm{a} \mathrm{r} 0$ i , $1452 b 36,53 b 39,54 a 2)$
\end{abstract}

${ }^{2}$ Halliwell 1986, 170 especially note 3 observes that the association of fear and pity with poetry can be found in Gorgias, Plato, and Sophocles, and as far back as Homeric epic.

${ }^{3}$ That anger admits of catharsis seems to follow not only because Aristotle seems to allow for catharsis in regard to the emotions generally, but also because he mentions becoming enraged (ełor gizw) as part of a cathartic response to sacred music (Pol. 1342a4-16).

${ }^{4}$ Aristotle discusses anger at various points throughout his works. Particularly significant discussions are to be found in Top. 156a30-b2, De An. 403a25-403b9, EN 1125b26-1126b10, and Rhet. 1378a31-1380b33.

5 The Poetics does not offer examples of anger in the tragedies, but the Rhetoric notes its presence in Antiphon's Meleager (1379b13-16) as well as in Homer (cf. 1378b5-9, 31-34, 1379a4-6, 1380b20-30).

${ }^{6}$ Janko 1987,124 seems to take the mention of anger in this passage to place it on a par with fear and pity. Thus he claims that 'the emotions that tragedy arouses are not restricted to pity and terror.' I think Belfiore 1992, 226 is right to observe that the context for Aristotle's remark is 'a general account of the "rhetorical" (1456b35) uses of dianoia, and should not be taken as an indication that it is the function of tragedy to arouse anger as well as pity and fear.' Thus while the passage makes it abundantly clear that anger, as well as fear and pity, are presented on stage, nothing follows about its arousal in spectators. Even so, might one infer anger's presence in the reactions of spectators from its depiction on stage or its use in speech? But Aristotle supposes that faced with anger, one will be moved to fear, not anger. For example, he claims that the enmity or anger of someone with power has the ability to beget fear (Rhet. 1382a27-b1). Thus a 


\section{Aristotle's Exclusion of Anger From the Experience of Tragedy}

spectator upon viewing the anger of a character (if moved) is liable to be moved to fear, not to anger.

${ }^{7}$ Translations from the Poetics are or are based on Janko 1987. Translations from the Rhetoric are or are based on Kennedy 1991. All other translations are those provided by Barnes 1985.

${ }^{8}$ Being moved to fear and pity, rather than simply being spectators of them and their conditions, is readily read into much that Aristotle writes about the passions in the Poetics. So understanding matters makes the best sense of the Poetics as a whole, provides greater continuity with Plato's concerns for poetry, and Aristotle's thoughts on the relationships between cognitive change and the emotions.

${ }^{9}$ The hope must remain hope only. If it involves the impression that the hoped for is near at hand and fearful things are far off or non-existent, one is confident rather than fearful (Rhet. 1383a15-17).

${ }^{10}$ Belfiore 1992 offers the most thorough contemporary study of fear and pity in the context of Aristotle's Poetics. I have spoken at more length on fear (Leighton 1988) and anger (Leighton 2002), though in neither am I concerned with their poetical realisation.

${ }^{11}$ This comparatively popular conception of how poetry works finds expression in commentaries on Aristotle, for example Butcher 1911, $261 \mathrm{ff}$.

${ }^{12}$ Not all identifications help. For example, upon viewing Oedipus Rex, it will not help if a spectator identifies strongly Oedipus' children. For this, on Aristotle's account, should beget fear, not pity (see Rhet. 1386a18-25). It will help, however, to identify with someone who is more distant and capable of pity, Tiresias or the chorus for example.

${ }^{13}$ That one can take those on stage to be sufficiently close (or like) so as to evoke these emotions seems plausible. We do see them as in some way close, intimates, ones whose life and well being is of concern to us. Moreover, as social creatures our concerns can be extended to various members of our community (EN 1097b8-13). See also notes 12, 15, and 25. Here and in what follows by speaking of fear or pity, I mean to consider what ensues from the vantage of the nature of each of the passions. This is not meant in a way that takes a stand on whether particular incidents beget one passion in a tragedy's audience, but not both passions. The question whether fear and pity must be co-present in tragedy is a difficult one, and one that I can pursue only in a schematic way here. The nature of the passions themselves does not require that they be mutually present. The fact that the form of tragedy and particular tragedies are seen by Aristotle to involve fear and pity, does not imply that all occasions of fear in a audience require pity and vice versa. Thus far, their co-presence does not seem indicated. Still, it could turn out that certain structural features of the tragedies themselves or the incidents portrayed ensure that being moved to one requires the other, e.g. the place of family relationships.

${ }^{14}$ Further evidence that this is how Aristotle sees matters can be gathered from his own quite general characterisation of the important features of tragic plots (see especially chapters 13 and 14), and his advice that playwrights begin with the general structure (1455a34-b11). One feature 


\section{Aristotle's Exclusion of Anger From the Experience of Tragedy}

of the understanding of fear and pity offered here is that the emotions need not be personalised to one's own case. While there can be understandings of the emotions in the theatre in which spectators personalise matters (Belfiore 1992, 235-6), the advantage of not requiring this is that it can better preserve the emotional reaction's relevance to a spectator's role as a viewer of tragedy. See the discussion of watching the Antigone (to follow).

15 To be an apt emotion of tragedy not only need the emotion be of the right kind, and aroused by tragedy, but also aroused towards those close, $\mathrm{f} \mathrm{i} \mathrm{l}_{\mathrm{O}} \mathrm{i}$, kith and kin - certainly not enemies or strangers (cf. 1453b11-18). This claim seems a strengthening of the point that fear and pity are felt for those one knows or is close to. Here too there seems no reason to doubt that anger can concern those equally close. Thus here too anger remains on an equal footing with fear and pity.

${ }^{16}$ Anger's connection to revenge displays some concern for the immediate future. In saying that anger takes no account of the future, Aristotle seems to be stressing anger's immediacy, and denying it concerns for the long term or more distant matters. My thanks to R. Polansky for drawing this matter to may attention.

${ }^{17}$ This point can be made about fear also. For its definition indicates that the evil feared is one in the future.

${ }^{18}$ A stronger argument is tempting, namely, that the causes of anger are irrelevant to tragedy, whereas matters of destruction and danger are of its essence. I, however, can find no reason to conclude at the outset that tragedy must not deal with matters of belittlement. Indeed, as the treatment of Antigone and Tiresias (discussed earlier) indicates, matters of belittlement and responses of anger may be vital to the plots of particular tragedies. Thus the issue becomes why, given Aristotle's understanding of fear, pity and anger, there is not (and should not be) room for anger in the reactions of spectators. I shall return to this matter at the end of the essay.

${ }^{19}$ Whereas many of the arguments on offer have to do with the specific nature of anger, the present argument speaks to the problem of multiple emotional reactions to tragedy. It, more than the others, gives reason to suppose not only that Aristotle is not including anger as central to tragedy, but also that he is not likely to include most other emotional reactions.

${ }^{20}$ Indeed, if Belfiore 1992, 231 is right in suggesting that tragedy properly deals with only those situations in which fear and pity complement each other, the balancing will eliminate the tension altogether. Quite what counts as complementing and balancing versus conflicting is a delicate matter that depends very much on the particularities of the situation, the way and extent to which the poet moves the audience. Generally speaking one can suppose that fear and pity are readily balanced where one's emotional reactions concern the same disaster - so long as one is sympathetic to the plights of those involved. However, even here the dreadful might drive out the pitiable. One might be so attached to a character or so moved by their disaster that one might not be able pity another. The poet, then, will have to be masterful in begetting spectators' emotions. As in ethical matters, much rests on perception of the situation.

${ }^{21}$ Concern for the disruption of tragedies might seem capricious, but it seems that spectators' reactions could be extreme and a problem. It is in this sense that I suggest that Aristotle would 


\section{Aristotle's Exclusion of Anger From the Experience of Tragedy}

not want the audience to participate in the action of a play. This does not oppose the notion that the audience can participate in the action of the play in the sense that, for example, the plays can address the audience or that the audience might be taken to be participating in rites on stage (Belfiore 1992, 27).

${ }^{22}$ That catharsis itself is pleasant is suggested in the Politics (1342a1-16).

${ }^{23}$ Belfiore 1992, 262-265 gives an excellent summary of the many possible interpretations of catharsis. In order to beg as few question as possible, I make my argument while remaining as neutral as possible concerning the precise specification of poetical catharsis. See also note 24.

24 There is a further and potentially substantial argument from the nature of catharsis. If we take it that poetical catharsis is not (merely) a release and relief, but in some way (also) an intellectual clarification, then a satisfactory account of the poetical catharsis of the emotions should enable a specification of any cognitive implications of the catharsis of fear, pity and anger. Presumably this specification will involve the structural features of the emotions themselves (discussed above). In addition, the catharsis of these emotions is liable to have its own particular cognitive repercussions. If so, this too may prove be revealing. But because so very much will depend on precisely what catharsis proves to be, and since we remain far from a clear and detailed specification of that notion, I note the point, but here do not attempt to advance further the argument. My thanks to R. Polansky for pointing out the importance of this possibility.

${ }^{25}$ Earlier, I noted certain differences between the account of the emotions in the Rhetoric versus particular claims made in the Poetics. The differences seem to be qualifications in light of poetical concerns. Still, the evidence for specially designated poetical emotions seems lacking. That said, the understanding of how the emotions operate in the present context certainly varies. Butcher 1911, 254, for example, speaks of tragic excitation, with the morbid elements of fear and pity being thrown off, and the lower forms of the emotion being transmuted into higher and more refined forms. Belfiore 1992, chap 7, especially 235-8 takes there to be sufficient evidence to infer tragic fear and pity - though she does so without suggesting that they are different emotions or special aesthetic emotions. Interestingly, the Philebus' examination of malice, as well as laying out the general conditions for the emotion, seems to be working towards specially adapted conditions for its use in comedy (48b-50e).

${ }^{26}$ An argument for a final cause leading to action is more difficult to mount for pity, beyond the role of pain. Aristotle does not speak of it in terms of, say, appreciating or redressing life's injustices. So, for purposes here, I restrict my argument to fear. However, as with fear I do not deny that some connections between pity and activity must be plausible within Aristotle's framework. For example, consider that in the courts appeals to pity seem aimed to make jurors more lenient (cf. Rhet 1386b1-5). While that is fundamentally a matter of changing one's judgments, in context it is a performative that can be seen as a certain sort of action.

${ }^{27}$ I take Aristotle's claim about fear's connection to deliberation to indicate that fear begets the capacity or liability to deliberate. An anonymous reader has suggested that the passage should be understood to mean that fear yields deliberation. Both readings seem possible. Given this, I 


\section{Aristotle's Exclusion of Anger From the Experience of Tragedy}

provide arguments that assume fear yields the capacity/liability to deliberate, and also arguments that assume fear yields deliberation.

${ }^{28}$ Again, as the arguments in the first half of the present section have meant to explain, because the desire for revenge is part of anger, a similar possibility is unavailable to one made angry.

${ }^{29}$ W.W. Fortenbaugh classifies fear together with anger as practical emotions (Fortenbaugh 1975, 79-81), a position that I have supported (Leighton 1988, 76-99; 1996, 211). As I hope will be clear, my point is not now to deny either that anger is a practical emotion or that fear has practical realisations, but to argue that Aristotle's account of fear (as we might hope, given its role in poetry) also allows for non-practical realisations. Fear leading to flight or other action, doing so through deliberation, is but one realisation of the emotion. Granting that fear's deliberative propensity need not be actuated or that when actuated it may lead to deeper understanding rather than to action, seems truer to what Aristotle says about fear in the Rhetoric, and also renders fear's non-practical role in the Poetics feasible.

${ }^{30}$ Indeed, at times the disaster feared or pitied would seem to be a character's belittlement, e.g. Achilles and Priam. See note 18.

${ }^{31}$ It might be objected that the present project can not be illuminating because it wrongly assumes that Aristotle's specification of tragedy involves the emotional response of the spectators, including the thought that catharsis is something that occurs in the emotional lives of spectators. The objection cannot be met here. But so long as it will be allowed that tragedy, the emotions identified in tragedy's definition and catharsis do move (however secondarily) spectators, then the arguments offered here that there are conflicts arising between anger and fear and pity will emerge once more - if anger is roused by tragedy. If so, then Aristotle has reason to exclude anger from the reactions of spectators to tragedy, and as an emotion integral to tragedy in the ways of fear and pity. See also note 8.

Finally, I would like to thank R. Bosley, L. Judson, R. Polansky, and a number of anonymous readers for their thorough scrutiny of earlier versions of this paper. 